\title{
OPTIMASI KEKASARAN PERMUKAAN PROSES PEMBUBUTAN BAJA ST.42 DENGAN MENGGUNAKAN METODE TAGUCHI
}

\author{
Said Apreza ${ }^{1)}$, Zaldy Kurniawan ${ }^{2)}$, Muhammad Subhan ${ }^{2)}$ \\ ${ }^{1)}$ Mahasiswa Jurusan Teknik Mesin dan Manufaktur Politeknik Manufaktur Negeri Bangka Belitung \\ ${ }^{2)}$ Dosen Jurusan Teknik Mesin dan Manufaktur Politeknik Manufaktur Negeri Bangka \\ Kawasan Industri Air Kantung, Jalan Timah Raya Sungailiat Bangka 33211 \\ Telp. (0717) 93586, Fax. (0717) 93585 \\ e-mail:polman@polman-babel.ac.id
}

\begin{abstract}
Minimal surface roughness value is the performance to be achieved in the process of CNC NLX 2500 , is necessary to regulate variables NLX 2500 CNC process in order to obtain the proper response surface roughness of the workpiece is minimal.research that has been done is to determine the contribution of these variables NLX CNC process in 2500 to reduce the variation of the response surface roughness of the workpiece simultaneously. Moreover, it also made the determination that the proper setting of the variables NLX2500 CNC process in order to obtain the surface roughness of the workpiece is minimal.machining process variable is varied spindle rotation, motion eat, and in the funeral. The experimental design is determined based on the Taguchi method and form of orthogonal L9 (33). Optimization method is used Taguchi. The randomized trial with replication 2 times to overcome interference factors that occur during the machining process.the results showed that to reduce the variation of the response simultaneously, eat motion has the largest percent of the contribution, which amounted to $99.48 \%$, spindle rotation has a percent contribution of $0.0974 \%$, the feeds have a percent contribution of $-0.126 \%$.to obtain a surface roughness of the workpiece is minimal, spindle rotation is set at $2748 \mathrm{rpm}$, eating motion is set at $0.15 \mathrm{~mm} /$ rotation, the funeral was adjusted to $0.5 \mathrm{~mm}$.
\end{abstract}

Keywords: CNC NLX, surface roughness, Taguchi method, Variable

\begin{abstract}
Abstrak
Nilai kekasaran permukaan yang minimal merupakan kinerja yang ingin dicapai pada proses CNC NLX 2500, perlu dilakukan pengaturan variabel-variabel proses CNC NLX 2500 yang tepat agar diperoleh respon kekasaran permukaan benda kerja yang minimal. Penelitian yang telah dilakukan bertujuan untuk menentukan kontribusi dari variabel-variabel proses CNC NLX 2500 untuk mengurangi variasi dari respon kekasaran permukaan benda kerja secara serentak. Selain itu, juga dilakukan penentuan seting yang tepat dari variabel-variabel proses CNC NLX2500 agar diperoleh kekasaran permukaan benda kerja yang minimal. Variabel proses pemesinan yang divariasikan adalah putaran spindle, gerak makan, dan dalam pemakanan. Rancangan percobaan ditetapkan berdasarkan metode Taguchi dan berupa matriks ortogonal $L_{9}\left(3^{3}\right)$. Metode optimasi yang digunakan adalah Taguchi. Percobaan dilakukan secara acak dengan replikasi sebanyak 2 kali untuk mengatasi faktor gangguan yang terjadi selama proses pemesinan. Hasil penelitian menunjukkan bahwa untuk mengurangi variasi dari respon secara serentak, gerak makan memiliki persen kontribusi terbesar, yaitu sebesar 99,48\%, putaran spindle memiliki persen kontribusi sebesar 0,0974\%, dalam pemakanan memiliki persen kontribusi sebesar -0,126\%. Untuk memperoleh kekasaran permukaan benda kerja yang minimal, putaran spindle diatur sebesar $2748 \mathrm{rpm}$, gerak makan diatur sebesar $0,15 \mathrm{~mm} /$ putaran, dalam pemakanan diatur sebesar $0.5 \mathrm{~mm}$.
\end{abstract}

Kata Kunci: CNC NLX, kekasaran permukaan, metode Taguchi, variabel

Optimasi Kekasaran Permukaan Proses Pembubutan Baja ST.42 dengan Menggunakan Metode Taguchi (Zaldy Kurniawan) 


\section{PENDAHULUAN}

Seiring dengan perkembangan ilmu pengetahuan dan teknologi, suatu hasil produksi harus diimbangi dengan peningkatan kualitas hasil produksi, khususnya pada proses produksi yang menggunakan mesin perkakas seperti mesin bubut[1]. Dengan adanya mesin tersebut akan mempermudah dalam pembuatan komponen-komponen mesin dengan ketelitian tinggi dan efisien.

Proses pemotongan benda kerja yang baik, maka diperlukan pemilihan seting variabel yang tepat. Dan juga, pahat bubut menjadi salah satu faktor dalam proses pemotongan dimesin bubut. Mempertimbangkan hal tersebut, maka material yang digunakan dalam pelaksanaan penelitian adalah material baja karbon rendah St.42, Pemilihan material juga berpengaruh pada hasil pembubutan terutama berkaitan dengan kualitas kekasaran permukaan. Dari uraian diatas, penelitian mengenai pengaruh seting variasi kecepatan spindle, gerak makan dan kedalaman pemakanan terhadap tingkat kekasaran.

Dalam penelitian [2] menggunakan material St.42 dari hasil penelitian diperoleh variabelvariabel yang berpengaruh terhadap kekasaran adalah variabel sudut modifikasi, gerak makan dan kecepatan potong. Nilai kekasaran yang diperoleh yaitu $2.2344 \mu \mathrm{m}$, dimana nilai kekasaran tersebut dari kombinasi variabel sebagai berikut, kecepatan potong $57.5 \mathrm{~m} /$ menit, sudut modifikasi $99.6^{\circ}$, dan gerak makan 0.08 putaran/menit. [3] Proses pembubutan baja St.42 dengan model analisa dua arah, dengan dua variabel bebas dan satu variabel terikat. Pada feeding $0.05 \mathrm{~mm} /$ put dan cutting fluid yang berbeda, nilai kekasaran permukaan yang paling rendah adalah media pendingin air. Dari hasil pengujian tersebut menunjukkan bahwa media pendingin air merupakan yang paling baik, karena air dapat menyerap panas lebih baik dari semua variasi cutting fluid sehingga gesekan antara chip, tool dengan benda kerja sangat kecil.

Dari uraian di atas, maka dilakukan suatu penelitian dalam penggunaan feeding untuk mendapatkan nilai kekasaran yang diinginkan terhadap perbandingan hasil kekasaran permukaan benda kerja dengan menggunakan pahat bubut jenis Carbide dengan material St.42. Dari latar belakang tersebut maka akan dilakukan penelitian dengan judul Optimasi Kekasaran Permukaaan Proses Pembubutan Baja St.42 Dengan Menggunakan Metode Taguchi".

\section{METODE PENELITIAN}

a) Material penelitian

- Benda kerja

Benda kerja yang digunakan pada penelitian ini terbuat dari baja St.42 dengan ukuran diameter $50 \mathrm{~mm}$ dan panjang $100 \mathrm{~mm}$. ukuran dan bentuk benda kerja tersebut ditunjukkan pada Gambar 1.

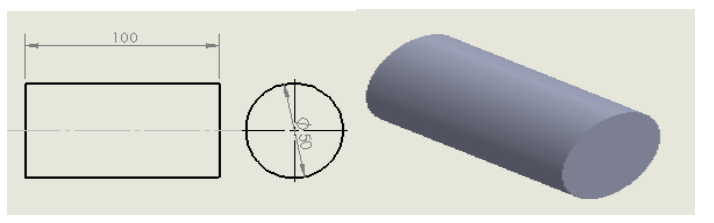

a)Ukuran b) Bentuk benda kerja

Gambar 1. Ukuran dan bentuk benda kerja

\section{b) Peralatan penelitian}

Mesin CNC NLX 2500 yang digunakan adalah buatan Jepang dengan spesifikasi sebagai berikut :

- Merk Mitsubishi

- Tipe NLX 2500

- Tahun pembuatan 2011

- Surface roughness tester

Surface roughness tester digunakan untuk mengukur kekasaran permukaan benda kerja yang dihasilkan dari suatu proses pemesinan. [4] Surface roughness tester yang digunakan dalam penelitian ini adalah Mitutoyo SJ 400 dengan kecermatan 0,001 ųm. 
c) Benda kerja hasil proses permesinan CNC NLX 2500

Bentuk benda kerja yang telah diproses dengan menggunakan mesin CNC NLX 2500 ditunjukkan pada Gambar 2.
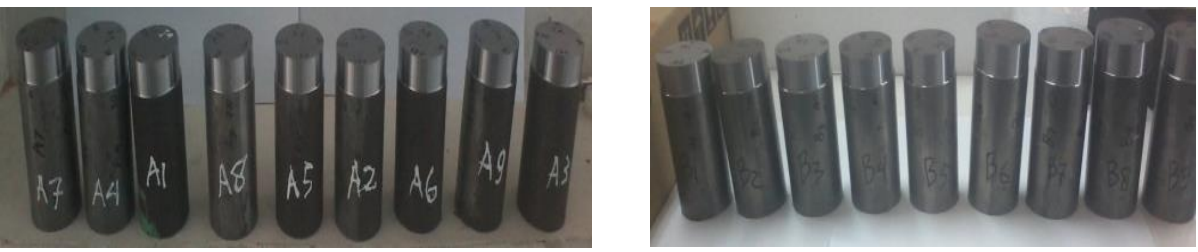

Gambar 2. Benda replikasi 1dan replikasi 2

d) Pengambilan data kekasaran permukaan

Benda kerja yang dikerjakan dengan mesin dan dilakukan pemotongan pada permukaannya tidak dapat rata atau halus sama sekali, tetapi akan meninggalkan bekas berupa lembah dan puncak yang disebut kekasaran permukaan. [5] Kekasaran rata-rata secara aritmatis $\left(R_{a}\right)$ dihitung berdasarkan harga rata-rata dari nilai absolut jarak antara profil terukur dengan profil tengah. Secara matematis dapat dirumuskan sebagai berikut:

$$
R_{a}=\frac{1}{n} \sum y(\mu \mathrm{m})
$$

(1)

\section{e) Rancangan percobaan}

Dalam penelitian ini dipilih tiga variabel proses. Satu variabel proses memiliki tiga level. Rancangan percobaan yang ditetapkan menggunakan metode Taguchi (orthogonal array L9)[6]. Percobaan dilakukan secara acak dengan replikasi sebanyak dua kali untuk mengatasi variabel gangguan yang terjadi selama proses pemesinan.

f) Menghitung rasio $\mathrm{S} / \mathrm{N}$ variabel respon

Karakteristik kualitas dari respon yang digunakan dalam percoabaan ini adalah semakin kecil semakin baik atau small is better untuk respon kekasaran permukaan. Perhitungan nilai rasio S/N untuk respon kekasaran permukaan dilakukan dengan menggunakan perangkat komputasi statistic. Rasio $\mathrm{S} / \mathrm{N}$ untuk karakteristik ini dirumuskan dengan persamaan sebagai berikut [7]:

$$
\mathrm{S} / \mathrm{N}=-10 \log \left[\sum_{i=1}^{n} \frac{y_{i}^{2}}{n}\right]
$$

(2)

\section{g) Menentukan kondisi variabel untuk respon optimal}

Penentuan kondisi variabel terbaik diawali dengan membuat tabel variabel respon untuk memudahkan pemilihan level dari variabel yang menghasilkan respon optimal.

h) Prediksi nilai hasil optimasi

Perhitungan prediksi nilai hasil optimasi dapat dihitung dengan persamaan rumus (2):

$$
\hat{\eta}=\eta_{m}+\sum_{i=1}^{q}\left(\bar{\eta}_{1}-\eta_{m}\right)
$$
dengan:

$\eta_{m}=$ Nilai rata-rata dari keseluruhan kekasaran

$\bar{\eta}=$ Rata-rata kekasaran pada level optimal

$q=$ Jumlah variabel yang mempengaruhi respon secara signifikan

\section{i) Analisis variansi dan persen kontribusi}


Analisis variansi (ANAVA) digunakan untuk mengetahui variabel proses yang meliki pengaruh secara signikan terhadap respon. Persen kontribusi yang menunjukkan porsi (kekuatan relatif) masingmasing variabel proses terhadap total variansi dari respon yang diamati. Jika persen kontribusi error kurang dari lima belas persen, maka tidak ada variabel yang berpengaruh terabaikan tetapi jika persen kontribusi error lebih dari lima belas persen mengindikasikan ada variabel yang berpengaruh terabaikan.

\section{j) Melakukan pengujian konfirmasi}

Percobaan konfirmasi merupakan percobaan yang dilakukan berdasarkan kombinasi variabel hasil optimasi. Tujuannya adalah untuk mencocokkan hasil prediksi dengan hasil respon secara actual.

\section{HASIL DAN PEMBAHASAN}

3.1 Penentuan pengaturan level variabel proses

Hasil penentuan pengaturan level pada masing-masing variabel proses ditunjukkan pada Tabel 1. Tabel 1. Pengaturan level-level variabel proses

\begin{tabular}{lcccc}
\hline \multicolumn{1}{c}{ Variabel Proses } & Satuan & Level 1 & Level 2 & Level 3 \\
\hline A Putaran spindle & $\mathrm{rpm}$ & 2053 & 2401 & 2748 \\
\hline B Gerak makan & $\mathrm{mm} /$ put & 0,15 & 0,27 & 0,60 \\
\hline C Dalam pemakanan & $\mathrm{mm}$ & 0,25 & 0,375 & 0,5 \\
\hline Sumber : Hasil Perhitungan & & &
\end{tabular}

Hasil percobaan berupa nilai kekasaran permukaan seperti ditunjukkan pada Tabel 2.

Tabel 2. Data hasil percobaan

\begin{tabular}{ccccc}
\hline $\begin{array}{c}\text { Seting } \\
\text { Kombinasi ke }\end{array}$ & $\begin{array}{c}\text { A } \\
\text { Putaran spindle } \\
(\mathrm{rpm})\end{array}$ & $\begin{array}{c}\text { B } \\
\text { Gerak makan } \\
(\mathrm{mm} / \text { put })\end{array}$ & $\begin{array}{c}\text { C } \\
\text { Dalam pemakanan } \\
(\mathrm{mm})\end{array}$ & $\begin{array}{c}\text { Kekasaran } \\
\text { permukaan } \\
\text { (ųm) }\end{array}$ \\
\hline 1 & 1 & 1 & 1 & 1,230 \\
\hline 2 & 1 & 2 & 2 & 2,798 \\
\hline 3 & 1 & 3 & 3 & 6,209 \\
\hline 4 & 2 & 1 & 3 & 1,055 \\
\hline 5 & 2 & 2 & 1 & 2,719 \\
\hline 6 & 2 & 3 & 3 & 5,856 \\
\hline 7 & 3 & 1 & 1 & 0,833 \\
\hline 8 & 3 & 2 & 2,693 \\
\hline 9 & 3 & 3 & & 6,043 \\
\hline Sumber : Hasil Perhitungan & Rata-rata & & 3,271 \\
\hline
\end{tabular}

\subsection{Nilai rasio $\mathrm{S} / \mathrm{N}$ untuk variabel respon}

Nilai rasio $\mathrm{S} / \mathrm{N}$ yang dihasilkan untuk variabel respon kekasaran permukaan ditunjukkan pada Tabel

3. dan masing-masing level ditunjukkan pada Tabel 4

Tabel 3. Rasio S/N untuk respon

\begin{tabular}{ccccc}
\hline $\begin{array}{c}\text { Seting } \\
\text { Kombinasi ke }\end{array}$ & $\begin{array}{c}\text { A } \\
\text { Putaran spindle } \\
(\mathrm{rpm})\end{array}$ & $\begin{array}{c}\text { B } \\
\text { Gerak makan } \\
(\mathrm{mm} / \text { put })\end{array}$ & $\begin{array}{c}\text { C } \\
\text { Dalam pemakanan } \\
(\mathrm{mm})\end{array}$ & Rasio S/N \\
\hline 1 & 1 & 1 & 1 & $-1,7946$ \\
\hline 2 & 1 & 2 & 2 & $-8,9362$ \\
\hline 3 & 1 & 3 & 3 & $-15,8604$ \\
\hline 4 & 2 & 1 & 2 & $-0,4661$ \\
\hline 5 & 2 & 2 & 3 & $-8,6866$ \\
\hline 6 & 2 & 3 & 1 & $-15,3526$ \\
\hline 7 & 3 & 1 & 3 & 1,5858 \\
\hline 8 & 3 & 2 & 1 & $-8,6047$ \\
\hline 9 & 3 & 3 & 2 & $-15,6252$ \\
\hline & & Rata-rata & & $-8,202212$ \\
\hline
\end{tabular}

Sumber : Hasil Perhitungan 
Tabel 4. Rata-rata kekasaran permukaan masing-masing level

\begin{tabular}{clccc}
\hline \multirow{2}{*}{ Simbol Variabel } & Variabel proses & \multicolumn{3}{c}{ Kekasaran permukaan (Ra) } \\
\cline { 3 - 5 } & & Level 1 & Level 2 & Level 3 \\
\hline A & Putaran spindle & 3,412 & 3,210 & 3,190 \\
\hline B & Gerak makan & 1,039 & 2,736 & 6,036 \\
\hline C & Dalam pemakanan & 3,260 & 3,299 & 3,254 \\
\hline \multicolumn{5}{c}{ Total nilai rata-rata Ra $=3,271$} \\
\hline
\end{tabular}

Plot rata-rata untuk tiap-tiap variabel proses untuk respon kekasaran permukaan ditunjukkan pada Gambar 3.

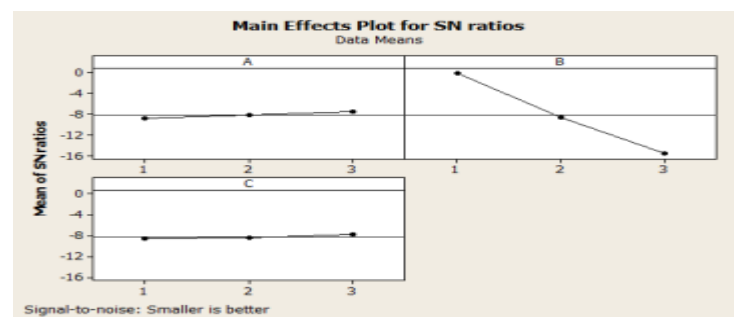

Gambar 3. Plot rasio S/N untuk respon kekasaran permukaan

\subsection{Penentuan kondisi variabel untuk respon optimal}

Penelitian ini menghasilkan kondisi variabel proses untuk respon optimal ditunjukkan pada Tabel 5. Di bawah ini:

Tabel 5. Kondisi variabel proses untuk respon optimal

\begin{tabular}{cccc}
\hline Simbol & Variabel proses & Tingkatan Level & Nilai Level \\
\hline A & Putaran spindle & Level 3 & 2748 rpm \\
\hline B & Gerak makan & Level 1 & $0,15 \mathrm{~mm} /$ put \\
\hline C & Dalam pemakanan & Level 3 & $0,5 \mathrm{~mm}$ \\
\hline Sumber : Hasil Perhitungan & &
\end{tabular}

\subsection{Prediksi nilai hasil optimasi}

Berdasarkan kondisi untuk respon optimal yang ditunjukan pada Tabel 6, sehingga dapat ditentukan prediksi nilai optimal. Perhitungan prediksi nilai hasil optimasi dapat dihitung dengan persamaan (3) dan diperoleh nilai sebesar 0,941

\subsection{Hasil analisis variansi (ANAVA)}

Tabel 6. Hasil analisis variansi (ANAVA)

\begin{tabular}{crrrrrrr}
\hline Source & DF & Seq SS & Adj SS & Adj MS & F & P-value & $\begin{array}{r}\text { Kontribusi } \\
(\%)\end{array}$ \\
\hline A & 2 & 0,0907 & 0,0907 & 0,0453 & 1,72 & 0,368 & 0,0974 \\
\hline B & 2 & 38,7379 & 38,7379 & 19,36907 & 732,70 & 0,001 & 99,48 \\
\hline C & 2 & 0,0036 & 0,0036 & 0,0018 & 0,07 & 0,936 & $-0,126$ \\
\hline Error & 2 & 0,0529 & 0,5029 & 0,0264 & & & 0,543 \\
\hline Total & 8 & 38,8850 & & & & & 100 \\
\hline \multicolumn{7}{l}{ Sumber : Hasil Perhitungan }
\end{tabular}

Dari hasil ANAVA menunjukkan bahwa variabel proses yang berpengaruh secara signifikan terhadap respon Ra yang diamati. Variabel proses yang berpengaruh secara signifikan terhadap respon apabila mempunyai nilai $F_{\text {hitung }}$ lebih besar dibandingkan $F_{\alpha, 02,02}$ (Nilai $F$ dilihat pada tabel statistic). Variabel-variabel proses yang memiliki persen kontribusi adalah putaran spindle, yaitu 0,0974 \%, dalam pemakanan memiliki kontribusi sebesar $-0,126 \%$, gerak makan memiliki kontribusi yang besar, yaitu sebesar $99,48 \%$. 


\subsection{Pengujian Konfirmasi}

Pengaturan variabel proses pada pengujian konfirmasi adalah $A_{3} B_{1} C_{3}$. Hasil perhitungan rasio $S / N$ pada kondisi awal dan kondisi optimal, prediksi dan pengujian konfirmasi, serta nilai Ra kondisi awal dan optimal dapat ditunjukkan pada Tabel 7.

Tabel 7. Hasil Pengujian Konfirmasi

\begin{tabular}{cccc} 
& \multirow{2}{*}{\begin{tabular}{c} 
Kombinasi \\
\cline { 3 - 4 }
\end{tabular}} & awal & Pombinasi Optimum \\
\cline { 3 - 4 } & $\mathrm{A}_{2} \mathrm{~B}_{2} \mathrm{C}_{2}$ & $\mathrm{~A}_{3} \mathrm{~B}_{1} \mathrm{C}_{3}$ & $\mathrm{~A}_{3} \mathrm{~B}_{1} \mathrm{C}_{3}$ \\
\hline Pengaturan variabel proses & 2,561 & 0,941 & 0,825 \\
\hline Kekasaran Permukaan & $67,78 \%$ & & \\
\hline Sumber : Hasil Perhitungan & &
\end{tabular}

\section{SIMPULAN}

Hasil penelitian menunjukkan bahwa kontribusi dari variabel-variabel proses dalam mengurangi variasi respon $\mathrm{Ra}$ adalah putaran spindle yaitu sebesar $0,0974 \%$, dalam pemakanan memliki persen kontribusi sebesar -0,126 \% dan gerak makan memiliki persen kontribusi yang besar, yaitu sebesar 99,48 \%. Kekasaran permukaan ( $\mathrm{Ra}$ ) yang maksimal maka variabel putaran spindle diatur sebesar $2748 \mathrm{rpm}$, gerak makan 0,15 $\mathrm{mm} /$ put dan dalam pemakanan 0,5 $\mathrm{mm}$. Pada penelitian selanjutnya disarankan, untuk melakukan optimasi dengan menggunakan metode-metode optimasi yang lain sebagai perbandingan dan menambahkan variabel-variabel proses lain yang memiliki pengaruh yang signifikan terhadap respon.

\section{DAFTAR PUSTAKA}

[1] Marsyahyo, “Eko, Mesin Perkakas Pemotongan Logam, Bayumedia”, Malang 2003.

[2] Danang Iswinarko, "Optimasi Kondisi Pemotongan Pahat Modifikasi Terhadap Kekasaran Permukaan Hasil Proses Bubut Lurus Material St.42 dengan Metode Response Surface", Universitas Jember, 2014.

[3] Febi Rahmadianto, "Pengaruh Variasi Cutting Fluid dan Variasi Feeding Pada Proses Pemotongan Orthogonal Poros Baja terhadap Kekasaran Permukaan," Institut Nasional Malang, 2015.

[4] Rochim, T, (2001), Proses Pemesinan, Institut Teknologi Bandung, Bandung

[5] Petropoulus, G.,Kechagias, J.,Akis, V.I.,dan Maropoulus,. Surface Roughness Investigation of a Reinforced Polymer Composite. International Conference on Economic Enggineering and manufacturing Systems, 2009.

[6] Montgomery, D.C, Design and Analysis of Experiment, John Wiley \& Sons, Inc, New York, 2009.

[7] Soejanto, "Desain Eksperimen dengan Metode Taguchi”, Graha Ilmu, Yogyakarta, 2009. 